\title{
A new corrosion inhibitor for zinc chamber treatment
}

\section{O.A. Goncharova,* Yu.I. Kuznetsov, N.N. Andreev, A.Yu. Luchkin, N.P. Andreeva and D.S. Kuznetsov}

A.N. Frumkin Institute of Physical Chemistry and Electrochemistry, Russian Academy of Sciences, Leninsky pr. 31, Moscow, 119071 Russian Federation

*E-mail: goncharova_oa@inbox.ru

\begin{abstract}
Thin organic films on metal surfaces can be obtained by adsorption of volatile (vaporphase) inhibitors (VCI), which, despite the extremely small thickness, provide high corrosion resistance under various atmospheric conditions. However, there is a problem in the practical application of compounds with high vapor pressure, namely, the air-tightness of the joint packaging of VCI and metal products. Infringement of packing air-tightness entails desorption of VCI from the metal surface followed by its corrosion.

A fundamentally new opportunity for creating thin films capable of preventing corrosion of metal products in a humid atmosphere during their transportation and inter-operation storage is opened by the treatment of an item or semi-finished product to be protected in hot vapors of non-toxic compounds with low volatility under normal conditions. They evaporate at elevated temperature $(t)$ in the enclosed space of a chamber and strongly adsorbed on the metal to create stable thin films that provide a long-term protective aftereffect under atmospheric conditions. This method of vapor-phase protection by chamber corrosion inhibitors has broad prospects of practical application.

It has been proven by a complex of accelerated corrosion, electrochemical and optical methods that chamber treatment of zinc with vapors of low volatile corrosion inhibitors at $t \leq 100^{\circ} \mathrm{C}$ is capable of forming films on zinc surface that possess a prolonged protective after-effect. It has been shown that short-term chamber treatment in the vapor of a new inhibitor, IFKhAN-121, provides effective temporary protection of zinc, both in accelerated tests and when exposed in the industrial atmosphere of Moscow for 1 year.
\end{abstract}

Received: June 27, 2018. Published: July 30, 2018

doi: $\underline{10.17675 / 2305-6894-2018-7-3-5}$

Key words: zinc, corrosion inhibitors, ellipsometry, EIS, corrosion tests, atmospheric corrosion, passivity.

\section{Introduction}

Zinc is one of the most important non-ferrous metals used in industry. While zinc is stable in dry atmospheres, it quickly corrodes at high humidity and in the presence of aggressive components in the air. In view of this, its protection against atmospheric corrosion is an important technical problem, which for a long time was solved by chromating [1]. 
However, the high toxicity of $\mathrm{Cr}(\mathrm{VI})$ compounds and stricter environmental requirements led to the need to replace chromates with non-toxic compounds. In fact, for zinc protection it was proposed to use organic compounds capable of forming thin protective coatings on it, including those that hydrophobize the surface [2-9].

Most often, such coatings are formed from the liquid phase [10]. Nevertheless, protective films on zinc surface can be obtained not only from solutions but also from the gas phase. To do this, volatile inhibitors are used [11-18], which adsorb on the surface of metals, forming adsorption layers capable of inhibiting corrosion. Typically, compounds or mixtures of compounds, that have a high equilibrium saturated vapor pressure $\left(p_{\mathrm{s}}\right)$ under normal conditions are used as VCIs.

The main condition and, at the same time, the main complexity of VCI application is the air-tightness of the joint packing of a VCI and metal products for the whole time of protection. Infringement of air-tightness of a package leads to evaporation of the inhibitor from the protected volume and its desorption from the metal surface, followed by initiation of corrosion. A solution to this problem may lie in the creation of VCIs that can be adsorbed from the vapor phase irreversibly to provide a prolonged protective after-effect (PAE).

Many studies have been devoted to the irreversible adsorption of VCIs [19-25]. However, we have to admit that even modern formulations of this type have a low PAE. Adsorption films with high PAE can be obtained by using the so-called chamber inhibitors (ChIn), which have low volatility under normal conditions, for vapor-phase protection of metals. It is recommended to perform the treatment of metals in their vapors at elevated temperatures, where the $p_{\mathrm{s}}$ of the compounds becomes many times higher. For example, rather a good efficiency of steel protection is provided by its one-hour treatment in hot vapor of octadecylamine (ODA) or its mixture with 1,2,3-benzotriazole (BTA) [26]. During this time, ultrathin films are formed on steel, preventing corrosion of these metals under conditions of periodic moisture condensation.

Important advantages of the chamber method of vapor-phase protection of metals are the absence of requirements for the air-tightness of the packing used for the temporary protection of metal items, as well as the expansion of the range of non-toxic and accessible reagents for performing vapor-phase passivation of metals. In view of this, in this article we studied the possibility of chamber passivation of zinc by a new domestic inhibitor of IFKhAN-121 in order to determine its effectiveness in the temporary protection of this metal against atmospheric corrosion.

\section{Experimental}

Flat specimens of zinc $(\mathrm{Zn}>99.975, \mathrm{Fe}<0.005, \mathrm{Al}<0.005, \mathrm{Cu}<0.001$, As $<0.0005$, $\mathrm{Pb}<0.013, \mathrm{Sn}<0.001, \mathrm{Cd}<0.004)$ measuring $25 \times 17 \times 6 \mathrm{~mm}$ had a hole for fastening in chambers and glass cells where the corrosion tests were conducted. Cylindrical electrodes of the same material with a diameter of $10 \mathrm{~mm}$ had a hole with threading for a mounting 
rod on one of their butt ends. The electrodes were pressed into Teflon shells to avoid exposure of the side surfaces to the electrolyte during the tests. The lower end of a cylindrical specimen was used as the working surface.

The protective after-effect of chamber treatment of specimens was estimated in corrosion and electrochemical experiments. Before the chamber treatment in ChIn vapors, the working surfaces of the specimens and electrodes were polished to a mirror finish using abrasive papers with grain sizes of $20-28 \mu \mathrm{m}$, degreased with acetone, and dried. Further, samples were mounted in $0.5 \mathrm{~L}$ sealed glass vessels containing a weighed portion of an inhibitor $(0.5 \mathrm{~g})$. The cells were placed into a drying cabinet for 1 hour. Its temperature ranged from 60 to $120^{\circ} \mathrm{C}$ in different experiments. After that, the cells were cooled for 15 minutes and the inhibitor was removed. The cells were again closed and kept for 24 hours at room temperature. After this time, the specimens and electrodes were subjected to corrosion and electrochemical tests.

In a series of corrosion tests with periodic condensation of moisture on the metal, the specimens were fastened on nylon threads to the lids of hermetic glass cells $(0.6 \mathrm{~L})$. Hot water $\left(50^{\circ} \mathrm{C}, 100 \mathrm{ml}\right)$ was poured at the bottom of each cell. Once a day, the cells were opened and the cooled water was changed to hot water. The change of water was combined with a visual inspection of the specimens. During the first 12 hours of exposure, the specimens were examined hourly without opening the cells.

The tests in neutral salt fog were performed in a WEISS SC 450 chamber at room temperature. Each one-hour test cycle included 15-minute spraying of $3 \% \mathrm{NaCl}$ solution followed by 45-minute exposure of specimens in the resulting salt fog. Specimens were inspected $55 \mathrm{~min}$ after the beginning of each cycle.

Environmental tests of the effectiveness of zinc chamber protection were carried out in the urban atmosphere of Moscow. The specimens were exposed under a shelter and visual inspection was performed every week. In the corrosion tests, the time $\tau$ before the first corrosion damage appeared on the specimens was recorded. Based on these values, the inhibition coefficients for metal depassivation were calculated:

$$
\gamma=\tau_{\text {prot, inh }} / \tau_{\text {prot, bg }} .
$$

Potentiodynamic experiments were performed using an IPC-pro potentiostat (RF) and a standard three-electrode cell with separated anodic and cathodic spaces. A platinum wire served as the auxiliary electrode. Potentials $(E)$ were measured against a saturated silver chloride reference electrode and converted to the normal hydrogen scale. The experiments were carried out in borate buffer solution ( $\mathrm{pH}$ 7.36) containing $0.001 \mathrm{M}$ sodium chloride. Electrodes were placed into a cell containing the electrolyte, kept for 3 min during which their potential $E$ stabilized, and polarized from the established potential $\left(E_{\mathrm{st}}\right)$ in anodic direction. The potential sweep rate was $0.2 \mathrm{mV} / \mathrm{s}$. Detection of the metal local depassivation was based on a sharp increase in the anodic current density $(i)$. After the experiment, the electrodes were removed from the electrochemical cell, blotted with filter paper and inspected visually. 
Electrochemical impedance spectra were obtained using a potentiostat of the same brand and a frequency response analyzer (FRA, produced in RF). The experiments were performed in a cell similar to that used in potentiodynamic experiments. Similarly to the latter, a silver chloride reference electrode and a platinum auxiliary electrode were employed, and borate buffer solution with $\mathrm{pH} 7.36$ containing $0.001 \mathrm{M}$ sodium chloride was used as the electrolyte. Electrodes were placed into a cell with the electrolyte and kept for 3 min before the measurements, which were performed at open circuit potential, using the $10 \mathrm{mV}$ amplitude of potential oscillations. The frequency was varied within the $0.1-$ $10^{5} \mathrm{~Hz}$ range. The results were processed using Dummy Circuits Solver software, version 2.1. The fit between the experimental and calculated data was no worse than $97 \%$.

The thickness of films $(d)$ formed on the metal under predefined conditions was measured with a Gartner manual ellipsometer with light beam modulation and advanced light detection. An LSM-S-111-10-NNP25 solid-state laser with diode pumping and a wavelength of $540 \mathrm{~nm}, \varphi=68.5^{\circ}$ was used as the radiation source. The accuracy in determining the angles of the polarizer and the analyzer was \pm 0.05 degrees. The experimentally determined values are the phase shift $\Delta$ and the angle of reduced polarization $\Psi$. The $d$ values were measured using the program available on the Spreadsheet Ellipsometry.html Internet resource in the single-layer model approximation.

The wetting angles of metal surfaces with distilled water $(\Theta)$ were estimated for a droplet $0.002 \mathrm{ml}$ in volume. A droplet was applied on a specimen surface and images were made with a specialized DCM 300 digital camera. $\Theta$ values were determined in the images using the angle meter available in PickPic graphic editor.

All the values presented in this paper are the averages from 5 to 7 independent experiments.

\section{Results and discussion}

The search for ChIn for temporary protection of zinc from corrosion among organic compounds of various classes and their mixtures with low $p_{\mathrm{s}}$ led to the creation of a new inhibitor IFKhAN-121. The high efficiency of the new ChIn was confirmed during tests under conditions of periodic moisture condensation (Table 1).

When analyzing the results, it is worth noting that zinc heat-treated without ChIn corroded within 30 minutes after the start of the test under conditions of periodic moisture condensation. Heat treatment of zinc in IFKhAN-121 vapor, even at a fairly low $t=60^{\circ} \mathrm{C}$, increased $\tau$ by a factor of 700 . With increasing the heat treatment temperature, the value of $\tau$ increased. Its maximum value (70 days) was observed at $t=100^{\circ} \mathrm{C}$. In this case, the value $\Theta=75-78^{\circ}$ indicates that the resulting film is hydrophilic. In our opinion, a further increase in $t$ to $120^{\circ} \mathrm{C}$ is impractical, since the protective effect does not increase but even decreases slightly. In view of this, further studies on the efficiency of IFKhAN-121 as a $\mathrm{ChIn}$ for zinc protection were performed on specimens heat-treated at $100^{\circ} \mathrm{C}$. 
Table 1. The results of accelerated tests under conditions of periodic moisture condensation on zinc specimens chamber-treated at elevated temperatures for 1 hour.

\begin{tabular}{ccc}
\hline $\boldsymbol{t},{ }^{\circ} \mathbf{C}$ & Without ChIn & IFKhAN-121 \\
\cline { 2 - 3 } & $\boldsymbol{\tau}$, days & $\gamma / \boldsymbol{\tau}$, days \\
\hline 60 & $\sim 0.02$ & $700 / 14$ \\
80 & $\sim 0.02$ & $2850 / 57$ \\
100 & $\sim 0.02$ & $3500 / 70$ \\
120 & $\sim 0.02$ & $3250 / 65$ \\
$20^{\circ} \mathrm{C}, 24 \mathrm{~h}$ & $\sim 0.02$ & $2 / 0.04$ \\
\hline
\end{tabular}

Potentiodynamic studies under the conditions described above have shown that the duration of exposure to air of zinc specimens pretreated in hot vapors of IFKhAN-121 affects their electrochemical behavior. In fact, exposure of a zinc specimen in air for 30 minutes reduces twofold the current density of zinc dissolution, $i_{\mathrm{an}}$. A further increase in air exposure time leads to an even greater decrease in $i_{\text {an }}$ and shifts the steady-state electrode potential $E_{0}$ to the positive direction. The maximum protective effect is achieved after 5 hours of exposure in air at room temperature. It can be assumed that during this time the protective layer undergoes self-organizing. This assumption is supported by the results of studies on the anodic behavior of zinc with a protective film formed in vapors of a new $\mathrm{ChIn}$ at $100^{\circ} \mathrm{C}$ for $0.5-72 \mathrm{~h}$ (Figure 1). It is significant that exposure to air of a zinc specimen after heat treatment without a ChIn for 5 or 24 hours had no effect on its electrochemical behavior.

The thicknesses of films formed on the surface of zinc at $100^{\circ} \mathrm{C}$ in a chamber without and with a ChIn were determined by the ellipsometric method. As can be seen from the results given in Table 2, the thickness $d$ of the air-borne oxide on zinc is $1 \mathrm{~nm}$. After heat treatment for 1 hour, the $d$ of the oxide film without the ChIn increased to $6.3 \mathrm{~nm}$. The changes in $d$ of the oxide film formed at $100^{\circ} \mathrm{C}$ in a chamber without IFKhAN-121 were determined after 1.5 and 24 hours of exposure in air. After one day, $d$ decreased by only $0.2 \mathrm{~nm}$ and amounted to $6.1 \mathrm{~nm}$. At the same time, the $d$ of the films adsorbed from IFKhAN-121 vapor at $100^{\circ} \mathrm{C}$ in 1 hour decreased from $119 \mathrm{~nm}$, as measured after 30 minutes of the zinc specimen exposure in air to 94 and $84 \mathrm{~nm}$ after 5 and 24 hours, respectively.

Based on the values of $d$ and wetting angles $\theta$, it can be concluded that the high PAE is caused by an increased thickness of the protective films rather than with hydrophobization of the surface. 


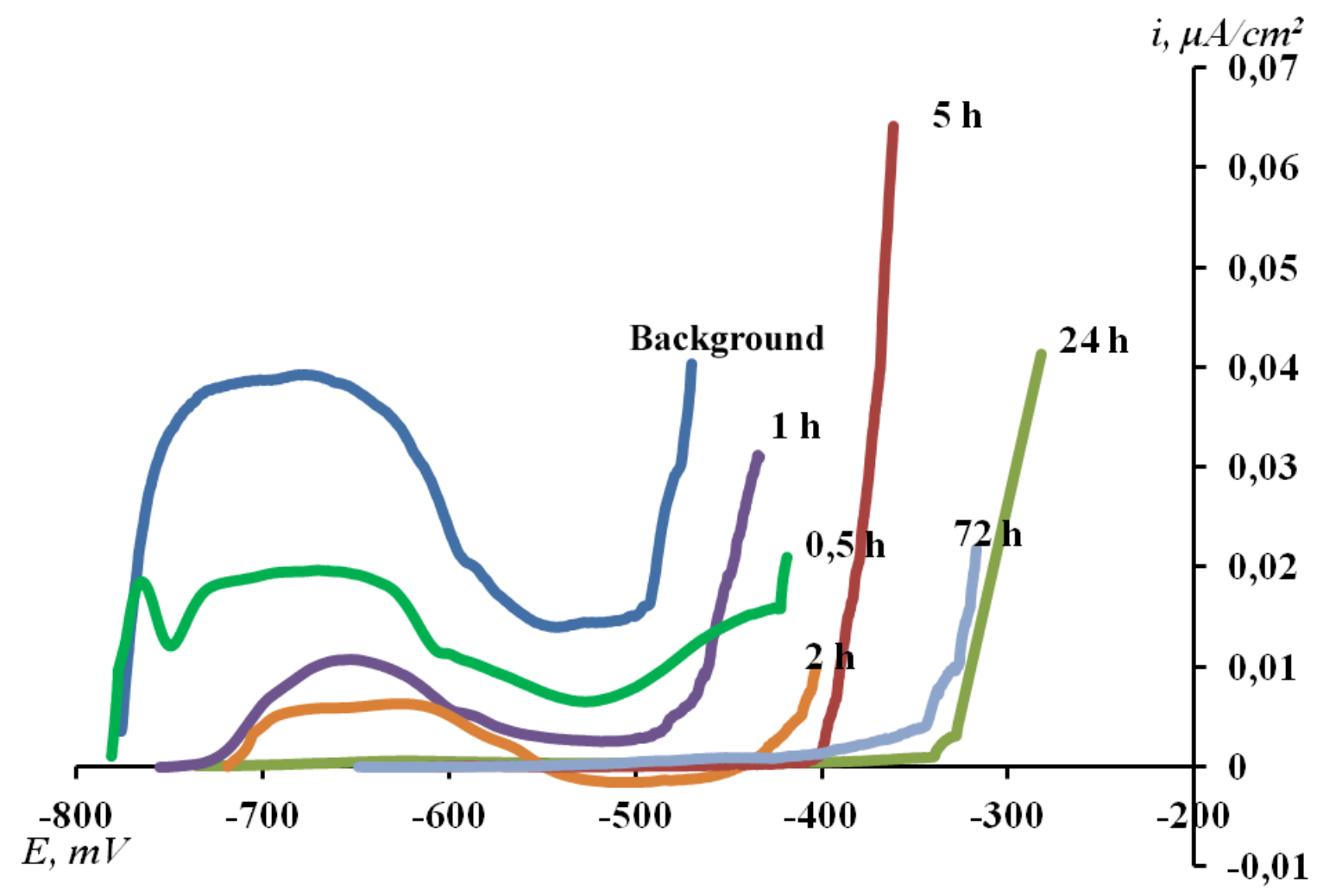

Figure 1. Anodic polarization curves of zinc in borate buffer with $\mathrm{pH} 7.36$ containing $1 \mathrm{mM}$ $\mathrm{NaCl}$ after treatment at $100^{\circ} \mathrm{C}$ in IFKhAN-121 vapors and without it (background) and after exposure of the electrode in air. The numbers at the curves indicate the duration of exposure of the electrode in air after treatment in inhibitor vapors (in hours).

Table 2. Variation in $d$ of films formed in IFKhAN-121 vapors at $100^{\circ} \mathrm{C}$ within 24 hours.

\begin{tabular}{ccc}
\hline ChIn & $\boldsymbol{\tau}$, hours & $\boldsymbol{d}, \mathbf{n m}$ \\
\hline Before treatment & - & 1 \\
\hline Without ChIn $\left(100^{\circ} \mathrm{C}\right)$ & - & 6.3 \\
\hline \multirow{3}{*}{ Without ChIn } & 0.5 & 6.3 \\
& 1 & 6.3 \\
& 5 & 6.2 \\
& 24 & 6.1 \\
\hline \multirow{2}{*}{ IFKhAN-121 } & 0.5 & 119 \\
& 1 & 104 \\
& 5 & 94 \\
\hline
\end{tabular}


The corrosion resistance of non-treated zinc and that after its treatment in ChIn vapor at $100^{\circ} \mathrm{C}$ was estimated by electrochemical impedance spectroscopy (EIS). Its parameters were calculated using an equivalent circuit typical of the corrosion of a metal coated with an inhibitor and presented in Figure 2 [27, 28]. The degree of protection of a zinc electrode was calculated by the formula:

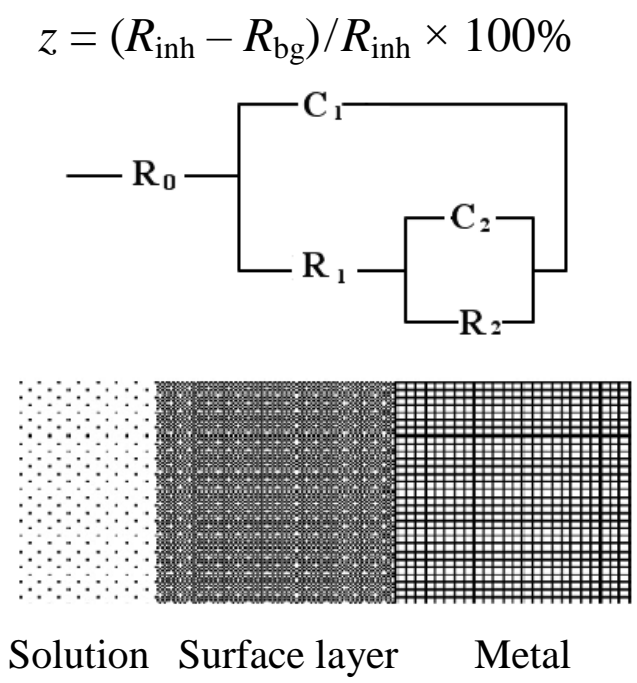

Figure 2. Equivalent circuit used to calculate the EIS parameters, where $R_{0}, R_{1}$ and $R_{2}$ are the solution, double electrical layer and interface resistances, respectively, $C_{1}$ is the capacitance of the double electrical layer, and $C_{2}$ is the capacitance of the protective film.

The impedance spectra for zinc without chamber passivation and with passivation in vapors of IFKhAN-121 are presented in Figure 3 in the form of Nyquist plots. The calculated values of parameters according to the presented schemes are given in Table 3 .

The hodograph for heat-treated zinc specimens in the absence of ChIn has the form of a semicircle. It is known [28] that a semicircle on the Nyquist plot reflects the charge transfer at the electrode/electrolyte interface, i.e. a double electric layer (DEL), and its diameter indicates how stable is the phase boundary for charge transfer. The values of $R_{1}$ and $R_{2}$ obtained for zinc heat-treated without a ChIn indicate that its corrosion resistance is low. After zinc treatment in hot vapors of IFKhAN-121, the diameter of the semicircle increases significantly compared to that for non-treated zinc, which indicates the high resistance of passivated zinc specimens for corrosion. The diameter of the semicircle on the Nyquist plot grows proportionally to the exposure time of these specimens in air, which correlates with the results of potentiodynamic measurements. It should be noted that exposure to air of zinc heat-treated without a ChIn does not lead to a change in its hodograph. 


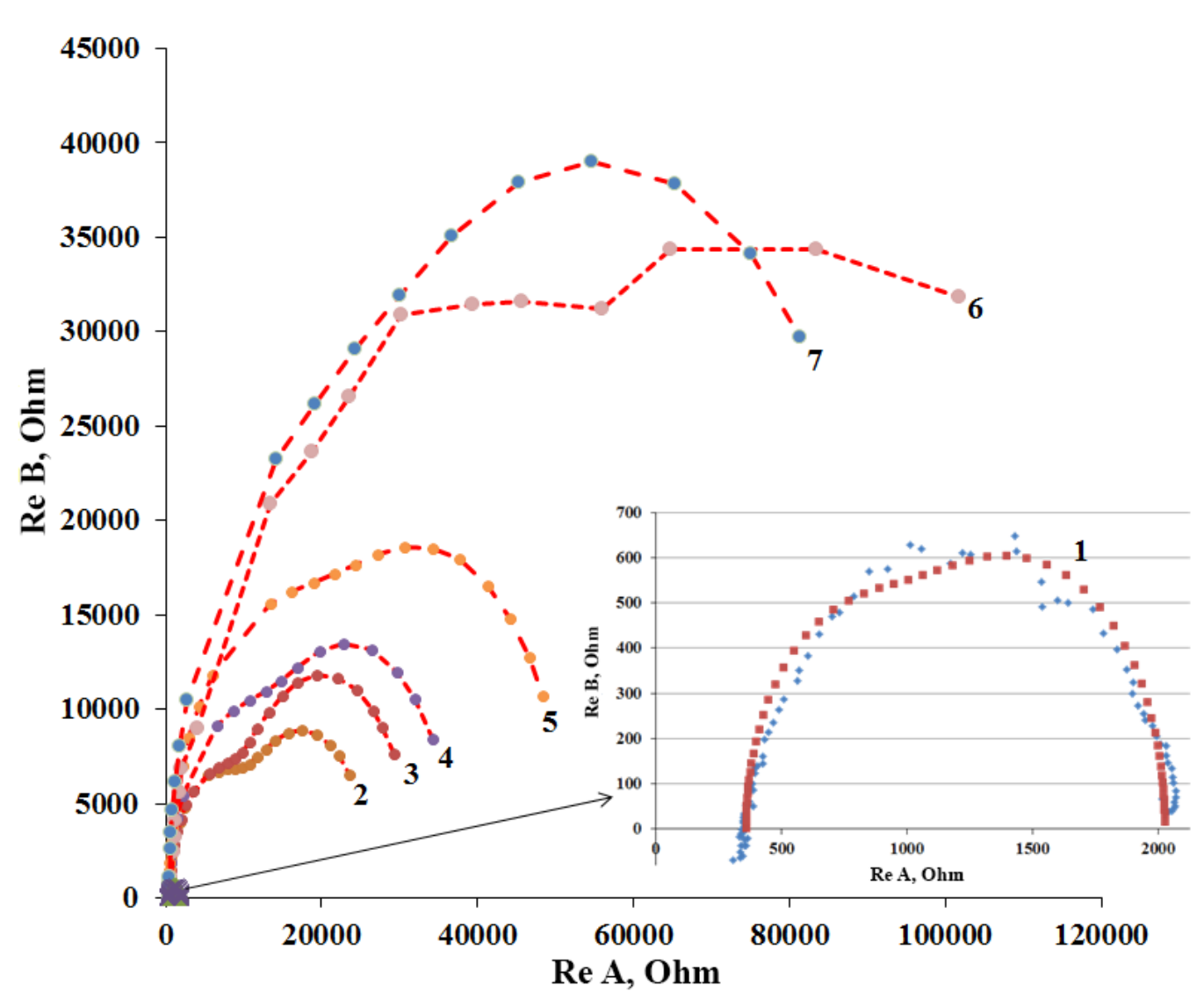

Figure 3. Nyquist plots of zinc specimens after chamber treatment $\left(100^{\circ} \mathrm{C}\right)$ without a ChIn 1 , or in vapors of IFKhAN-121 after exposure to air: $0.5 \mathrm{~h}-2,1 \mathrm{~h}-3,1.5 \mathrm{~h}-4,3 \mathrm{~h}-5$, $5 \mathrm{~h}-6,24 \mathrm{~h}-7$, dashed lines - model. Borate buffer solution ( $\mathrm{pH} 7.36$ ) containing $0.001 \mathrm{M}$ $\mathrm{NaCl}$.

Table 3. Impedance parameters calculated for various exposure times of zinc electrodes in air after heat treatment at $100^{\circ} \mathrm{C}$ in the presence and absence of ChIn.

\begin{tabular}{ccccccccc}
\hline & $\begin{array}{c}\boldsymbol{\tau} \\
\text { of air } \\
\text { exposure }\end{array}$ & $\boldsymbol{R}_{\mathbf{0}}, \mathbf{O h m}$ & $\begin{array}{c}\boldsymbol{R}_{\mathbf{1}}, \\
\mathbf{O h m} / \mathbf{c m}^{\mathbf{2}}\end{array}$ & $\begin{array}{c}\boldsymbol{R}_{\mathbf{2}}, \\
\mathbf{O h m} / \mathbf{c m}^{\mathbf{2}}\end{array}$ & $\begin{array}{c}\boldsymbol{C}_{\mathbf{1}}, \\
\boldsymbol{\mu} \mathbf{F} / \mathbf{c m}^{\mathbf{2}}\end{array}$ & $\begin{array}{c}\boldsymbol{C}_{\mathbf{2}}, \\
\boldsymbol{\mu} \mathbf{F} / \mathbf{c m}^{2}\end{array}$ & $\boldsymbol{S}$ & $\boldsymbol{z}, \boldsymbol{\%}$ \\
\hline $\begin{array}{c}\text { without } \\
\text { ChIn }\end{array}$ & & 360.311 & 989.703 & 678.162 & 5.48296 & 66.5433 & $3.23 \%$ & - \\
\hline & $0.5 \mathrm{~h}$ & 317.606 & 13109.2 & 12952.7 & 4.35816 & 38.3246 & $2.23 \%$ & 93.6004 \\
& $1 \mathrm{~h}$ & 418.834 & 13241.6 & 18343.8 & 3.51148 & 21.981 & $1.73 \%$ & 94.7195 \\
IFKhAN- & $1.5 \mathrm{~h}$ & 470.215 & 19285.4 & 17387.7 & 3.27542 & 20.9881 & $4.22 \%$ & 95.4521 \\
121 & $3 \mathrm{~h}$ & 418.387 & 30369.2 & 20983.1 & 1.68179 & 11.4665 & $3.75 \%$ & 96.7521 \\
& $5 \mathrm{~h}$ & 418.445 & 30366.7 & 20988.8 & 1.68147 & 11.4628 & $2.30 \%$ & 96.7523 \\
& $24 \mathrm{~h}$ & 494.612 & 49216.8 & 45494.5 & 1.09908 & 6.88712 & $3.22 \%$ & 98.239 \\
\hline
\end{tabular}


After chamber treatment of zinc in vapors of IFKhAN-121, the $R_{1}$ and $R_{2}$ values significantly increase, whereas $C_{1}$ and $C_{2}$ decrease with increasing time of exposure of the zinc electrode in air. In fact, the $R_{1}$ value increases 50-fold in 24 hours and $R_{2}$ increases 67fold. The increase in $R_{1}$ can be interpreted as a decrease in the corrosion rate, while that of $R_{2}$ indicates that the charge transfer process slows down due to the formation of a protective layer of ChIn. In 24 hours the $C_{1}$ value decreases 5-fold and $C_{2}$ decreases 9.66fold. The decrease in the double layer capacitance $C_{1}$ indicates that inhibitor molecules are adsorbed on the metal surface from vapors and prevent the access of charged particles to the surface. The decrease in $C_{2}$ also indicates a decrease in the corrosion rate. The decrease in the $C_{1}$ and $C_{2}$ values with an increase in the exposure time in the air of the specimens after heat treatment in the vapors of the new ChIn may indicate that self-organization of the film occurs, which leads to an increase in its protective properties. At the same time, the $z$ value increases with an increase in the time of exposure of zinc specimens in air from $93.6 \%$ after 0.5 hours to $98.24 \%$ after 1 day.

The protective ability of films formed on zinc during chamber treatment in vapors of IFKhAN-121 is also confirmed in more severe tests in a fog salt chamber. The first corrosion damage on zinc specimens that were not treated in vapors appeared after testing for 2 hours. Specimens treated in IFKhAN-121 vapor at $100^{\circ} \mathrm{C}$ began to corrode only after 72 hours, which in comparison with background specimens gives $\gamma \geq 36$. It is possible that longer exposure of zinc specimens in IFKhAN-121 vapors may provide better results.

Environmental tests of zinc specimens heat-treated in vapor of IFKhAN-121 were carried out under shelter in an urban atmosphere at the Moscow Corrosion Station of the A.N. Frumkin Institute of Physical Chemistry and Electrochemistry of the Russian Academy of Sciences. Under these conditions, zinc itself corrodes after 2 weeks, unlike the specimens pre-chambered in hot ChIn vapor $\left(100^{\circ} \mathrm{C}\right)$ whose corrosion damage was not observed even after 8 months of exposure. The first corrosion damage on the specimens passivated in vapors of IFKhAN-121 appeared in 9.5 months. However, after 12 months of exposure in the industrial atmosphere, the corroded area did not exceed $5 \%$ of the total surface area of the specimens. The next article will continue research into the mechanism of chamber treatment using ChIn in relation to zinc and galvanized steel in order to further improve its efficiency and improve the technology.

\section{Conclusions}

1. Treatment of items or semi-finished products made of zinc in vapors of the new corrosion inhibitor IFKhAN-121 at elevated temperatures $\left(\leq 100^{\circ} \mathrm{C}\right)$ can create an effective technology for temporary protection during their storage and transportation. This chamber treatment of zinc forms ultra-thin protective layers on the surface of zinc, ensuring its preservation under a shelter and without any packaging in the industrial atmosphere of Moscow for a period of more than 6 months. 
2. An increase in the protective capability of passivating chamber treatment of zinc in vapors of IFKhAN-121 after prolonged exposure in air at ordinary temperature $(5 \mathrm{~h})$ has been discovered, which allows us to assume that self-organization of the protective layer occurs, which is possibly accompanied by chemisorption of the inhibitor.

\section{Acknowledgements}

This study was carried out at A.N. Frumkin Institute of Physical chemistry and Electrochemistry of the Russian Academy of Sciences with support of the Russian Science Foundation (Grant No. 17-13-01413 "Fundamental principles of creation of ultra-thin passivating organic films on metals for protection against atmospheric corrosion").

\section{References}

1. B.R.W. Hinton and L. Wilson, Corros. Sci., 1989, 29, 967.

2. B. Müller and G. Imblo, Heterocycles as corrosion inhibitors for zinc pigments in aqueous alkaline media, Corros. Sci., 1996, 38, 293.

3. S. Manov, F. Noli, A.M. Lamazouere and L. Aries, Surface treatment for zinc corrosion protection by a new organic chelating reagent, J. Appl. Electrochem., 1999, 29, 995.

4. B. Muller and I. Forster, Corrosion inhibition of zinc pigments in aqueous alkaline media by aromatic hydroxy compounds, Corrosion, 1996, 52, 786.

5. G. Achary, H.P. Sachin, S. Shivakumara, Y. Arthoba Naik and T.V. Venkatesha, Surface treatment of zinc by Schiff's bases and its corrosion study, Russ. J. Electrochem., 2007, 43, 844.

6. R.L. Leroy, Mater. Perform., 1980, 19, 54.

7. R.L. Leroy, Corrosion, 1978, 34, 98.

8. R.L. Leroy, Corrosion, 1978, 34, 113.

9. H.Q. Liu, S. Szunerits, W.G. Xu and R. Boukherroub, Preparation of superhydrophobic coatings on zinc as effective corrosion barriers, ACS Appl. Mater. Interfaces, 2009, 1, 1150. doi: $10.1021 / \mathrm{am} 900100 \mathrm{q}$

10. M.O. Agafonkina, A.M. Semiletov, Yu.I. Kuznetsov, N.P. Andreeva and A.A. Chirkunov, Adsorption of sodium oleyl sarcosinate on zinc and its passivating action in a neutral aqueous solution, Korroz.: mater., zashch., 2016, no. 5, 15 (in Russian).

11. A.A. Mikhailov, Yu.M. Panchenko and Yu.I. Kuznetsov, Atmosfernaya korroziya $i$ zashchita metallov (Atmospheric corrosion and protection of metals), Pershina publishing house, 2016, Tambov, 555 pp. (in Russian).

12. I.L. Rosenfeld and V.P. Persiantseva, Ingibitory atmosfernoi korrozii (Inhibitors of atmospheric corrosion), Nauka, Moscow, 1985, 278 pp. (in Russian).

13. C. Fiaud, Theory and Practice of Vapour Phase Inhibitors, European Federation of Corrosion, The Institute of Materials, 1994, London, 163 pp. 
14. N.N. Andreev and Yu.I. Kuznetsov, Physicochemical aspects of the action of volatile metal corrosion inhibitors, Russ. Chem. Rev., 2005, 74, no. 8, 755.

15. N.N. Andreev and Yu.I. Kuznetsov, Volatile Inhibitors of Metal Corrosion. I. Vaporization, Int. J. Corros. Scale Inhib., 2012, 1, no. 1, 16. doi: 10.17675/2305-68942012-1-1-016-025

16. N.N. Andreev and Yu.I. Kuznetsov, Volatile inhibitors of metal corrosion. II. Interaction of systems being protected with the environment and corrosion prevention conditions, Int. J. Corros. Scale Inhib., 2012, 1, no. 2, 146. doi: 10.17675/2305-68942012-1-2-146-153

17. N.N. Andreev and Yu.I. Kuznetsov, Volatile Inhibitors of Metal Corrosion. III Principles and methods of efficiency estimation, Int. J. Corros. Scale Inhib., 2013, 2, no. 1, 39. doi: $10.17675 / 2305-6894-2013-2-1-039-052$

18. N.N. Andreev, O.A. Goncharova and S.S. Vesely, Volatile inhibitors of atmospheric corrosion. IV. Evolution of vapor-phase protection in the light of patent literature, Int. J. Corros. Scale Inhib., 2013, 2, no. 3, 162. doi: 10.17675/2305-6894-2013-2-3-162$\underline{193}$

19. N.S. Ovchinnikova, Yu.I. Kuznetsov, V.P. Persiantseva and L.T. Zhuravlev, Mass spectrometric studies of the products of $\beta$-diethyl aminoketone desorption from iron powder, Colloid J. USSR, 1975, 37, no. 5, 991.

20. R.A. Bulgakova，A.M. Dorfman, Yu.I. Kuznetsov，A.M. Liakhovich, V.I. Povstugar, N.P. Sokolova and O.V. Zamiatina, Formation of a protective layer on iron by adsorption of N,N-diethylaminopropionitrile, Zashch. Met., 1996, 32, no. 1, 48 (in Russian).

21. N.P. Andreeva, A.M. Dorfman, Yu.I. Kuznetsov and A.M. Liakhovich, On the adsorption of volatile corrosion inhibitor N,N-Diethylaminopropionitrile on iron, Zashch. Met., 1996, 32, no. 4, 403 (in Russian).

22. Yu.I. Kuznetsov, N.N. Andreev, N.P. Andreeva, D.V. Tolkachev and T.V. Fedotova, Inhibiting action and adsorption of $\beta$-aminoketones on metals, Zashch. Met., 1996, 32, no. 5, 528 (in Russian).

23. N.N. Andreev, N.P. Andreeva, R.Sh. Vartapetyan, Yu.I. Kuznetsov and T.V. Fedotova, Volatile corrosion inhibitors based on ethanolamines, Zashch. Met., 1996, 32, no. 5, 521 (in Russian).

24. Yu.I. Kuznetsov, The Role of Irreversible Adsorption in the Protection Action of Volatible Corrosion Inhibitors, CORROSION-98, NACE International, USA, 1998, Paper no. 242.

25. N.N. Andreev and Yu.I. Kuznetsov, Progress in the Fundamental of Volatile Inhibitors of Atmospheric Corrosion of Metals, In: Reviews on Corrosion Inhibitor Science and Technology, 2004, Vol. 3, Eds. A.Raman, P. Labine and V.A. Quraishi, 11-8 -11-18. 
26. A.Yu. Luchkin, O.A. Goncharova, N.N. Andreev and Yu.I. Kuznetsov, Steel protection by treatment with octadecylamine, 1,2,3-benzotriazole and mixtures thereof at elevated temperature, Korroz.: mater., zashch., 2017, no. 12, 20 (in Russian).

27. J.M. Ferreira, M. Oliveira, G.F. Trindade, L.C.L. Santos, C.R. Tomachuk and M.A. Baker, Development and characterisation of zinc oxalate conversion coatings on zinc, Corros. Sci., 2018, 137, 13. doi: 10.1016/j.corsci.2018.03.011

28. V.I. Kichigin, I.N. Sherstobitova and A.B. Shein, Impedans elektrokhimicheskikh $i$ korrozionnykh sistem (Impedance of electrochemical and corrosion systems), Perm, 2009, 238 (in Russian).

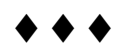

